\title{
Combined Cisplatin Treatment and Photobiomodulation at High Fluence Induces Cytochrome c Release and Cytomorphologic Alterations in HEp-2 Cells
}

\author{
Fatma Seragel-Deen ${ }^{1 *}$, Seham A. Abdel Ghani ${ }^{1}$, Houry M. Baghdadi ${ }^{1}$, Ali M. Saafan ${ }^{2}$ \\ ${ }^{1}$ Department of Oral Pathology, Faculty of Dentistry, Ain Shams University, Cairo, Egypt; ${ }^{2}$ National Institute of Laser Enhanced \\ Sciences, Cairo University, Cairo, Egypt
}

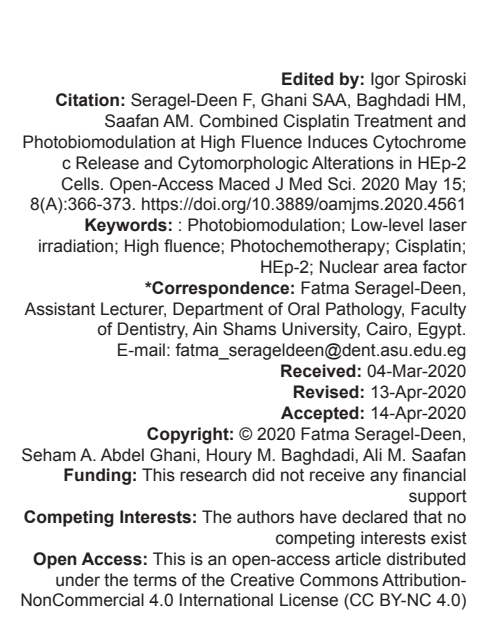

\section{Introduction}

Head and neck cancer (HNC), the sixth most common cancer in the world, is a grievous disease that claims as many as 300,000 lives each year, worldwide. Given the complexity of most head and neck anatomical sites, with consequent late detection and difficult surgical operability, the 5-year survival rate has been recently estimated to be ranging between $40 \%$ and $60 \%$ [1]

Cisplatin is a potent and widely used chemotherapeutic agent, being one of the first-line therapies for HNC [2]. Anticancer action of cisplatin is primarily mediated through induction of mitochondrial oxidative stress, leading to p53-dependent upregulation of proapoptotic Bax/Bak proteins, which allow for the exodus of cytochrome c (CYC) to the cytosol to further activate the executioner caspases 3,6 , and 7 of apoptotic death [3], [4].
Photobiomodulation (PBM) is a therapeutic approach that involves the use of LLL light in the visible red (600-700 nm) or near-infrared (NIR) (780$1000 \mathrm{~nm}$ ) spectrum, to induce biological alterations in the irradiated cells, through induction of a nonthermal photochemical reaction [5]. PBM has been classically adopted as a photobiostimulatory treatment for alleviation of pain associated with inflammatory conditions [6]. However, the photobioinhibitory aspect of low-level laser irradiation (LLLI) was revealed, as the laser light was found to obey "biphasic dose-response" or Arndt-Schulz law, which states that: "Low-dose is stimulatory, and high-dose is inhibitory" [7]. Likewise, in PBM, low dose of LLLI, in terms of low fluence $\left(\mathrm{J} / \mathrm{cm}^{2}\right)$, is stimulatory, while high dose or high fluence LLLI (HF-LLLI) is inhibitory or even lethal [8]. This "hormetic" effect of LLLI was exploited as a possible anticancer approach in many studies, which did exhibit an obvious phototoxic effect of PBM [9], [10], [11]. Intriguingly, the apoptotic effect 
exerted by PBM in prior studies was confirmed to be mitochondrially mediated [12], [13]

In the light of the fact that the mitochondrion represents a common target for both cisplatin- and PBM-mediated apoptosis, the present study aimed at investigating the potential synergistic phototoxic effect of PBM using HF-LLLI on cisplatin in a HNC cell line (HEp-2). The assessment of a possible apoptotic influence was at the molecular level by quantification of the amount of CYC released into the culture fluid after treatment, by enzyme-linked immunosorbent assay (ELISA), accompanied with direct visualization of PBMtreated cells by light microscope to examine the probable apoptotic cytological features present. Moreover, confirmation of apoptosis as the principal mechanism of cell death in PBM-treated HEp-2 cells, either alone or in combination with cisplatin, was performed through a quantitative computer-based nuclear morphometric analysis, to estimate nuclear area factor (NAF), which is a function of both nuclear size and shape.

\section{Materials and Methods}

\section{Cell culture}

Human laryngeal squamous cell carcinoma cell line HEp-2 (ATCC ${ }^{\circledR}$ CCL-23 ${ }^{\mathrm{TM}}$ ) used in this research work was kindly supplied from Cell Culture DepartmentVACSERA, Egypt. HEp-2 cells were grown in Dulbecco's modified eagle's medium (Invitrogen/Life Technologies), supplemented with $10 \%$ fetal bovine serum (HyClone), $2 \mathrm{mM}$ glutamine and sodium bicarbonate and antibiotics (100 units $/ \mathrm{ml}$ penicillin and $100 \mu \mathrm{g} / \mathrm{ml}$ streptomycin). The cultured cells were kept at $37^{\circ} \mathrm{C}$ in $95 \%$ air, $5 \% \mathrm{CO}_{2}$, in a humidified incubator. Then, HEp-2 cells were passage through Trypsin-EDTA solution $(0.25 \%)$ and phosphatebuffered saline (PBS) (all were purchased from SigmaAldrich, USA) and $\mathrm{pH}$ was maintained at 7.4.

\section{Cisplatin treatment}

Cisplatin drug (Sigma-Aldrich, USA) was supplied in a crystalline powder form, which was then dissolved in PBS to produce a stock solution of $5 \mathrm{mM}$ concentration and subsequently diluted with culture medium to create a series of cisplatin concentrations $(100,25,7.25,1.56$, and $0.39 \mu \mathrm{M})$. HEp-2 cells seeded in a flat-bottom 96-well plate were treated with the serial cisplatin concentrations for $24 \mathrm{~h}$. Some HEp-2 cells remained untreated and served as control.

\section{PBM}

The laser device used in this experimental work was a NIR $(808 \mathrm{~nm})$ semiconductor LLL diode (Photon,
Egypt). The output power was $350 \mathrm{~mW}$ and irradiation was adjusted to continuous wave mode (CW) for $3 \mathrm{~min}$ (180 s). The handpiece with a flat-top profile was held perpendicular and abutting the lid of the 96-well plate to deliver a homogeneous irradiation over each well, separately, in the darkness. Total energy conveyed to cells in each well, according to the equation: [Energy = irradiation time (seconds) $X$ power (in watts)], equaled $180 \times 0.35=63 \mathrm{~J}$. The irradiation area which was represented by growth space of the well, was measured to be $0.33 \mathrm{~cm}^{2}$. Hence, according to the equation: Fluence $=$ energy/area, the fluence calculated was equivalent to $63 / 0.33=190.91 \mathrm{~J} / \mathrm{cm}^{2}$. Some cultured HEp-2 cells, which did not receive cisplatin treatment, but were only irradiated, were assigned as PBM group. HEp-2 cells which were cisplatin-treated for $24 \mathrm{~h}$ and then irradiated, constituted the combination group (Cis+PBM).

\section{(3-[4,5-Dimethylthiazol-2-yl]-2,5-} diphenyltetrazolium bromide) (MTT) cytotoxicity assay

MTT cytotoxicity kit was purchased from Sigma-Aldrich, USA. This assay principally quantifies the viable fraction of cultured cells, based on their metabolic activity, as viable cells retain an active mitochondrial oxidoreductase enzyme that reduces the yellow tetrazolium salt in MTT solution into purple insoluble formazan crystals, which can be solubilized and quantified by spectrophotometric means. After incubation for $24 \mathrm{~h}$, the cells were further incubated for $4 \mathrm{~h}$ with $0.5 \mathrm{mg} / \mathrm{ml} \mathrm{MTT}$ reagent. After that, when the purple dye was obvious, the MTT solubilization solution was added. Absorbance values in each well were determined, as the optical density (OD) was measured by ELISA microplate reader (ROBONIK P2000 EIA reader, India) at a wavelength range of $490-630 \mathrm{~nm}$. The experiment was performed as 3-times repeats for each serial concentration, in both cisplatin-only treated HEp-2 cells (Cis) and Cis+PBM group. Besides, absorbance of PBM group as well as control cells was measured in triplicates. The absorbance mean of each group was calculated to be further used in the calculation of viability percentage, according to the equation [14]:

Viability $\%=$ (Absorbance mean of treated cells/absorbance mean of control cells) $\times 100$

\section{Calculation of half maximal inhibitory concentration $\left(I C_{50}\right)$ of cisplatin}

The treatment of HEp-2 cells with cisplatin at the serial concentrations of $100-0.39 \mu \mathrm{M}$, with and without PBM, yielded values of viability \% is shown in Table 1 . The values of viability $\%$ obtained from MTT assay were exploited to calculate $I_{50}$ (the maximal inhibitory concentration that suppresses the growth of $50 \%$ of treated cells) of cisplatin, through plotting a 
dose-response linear graph (Figure 1), depending on the equation $y=a x+b$, where the $X$-axis represents "the dose" or the logarithms of the cisplatin five graded concentrations $(100,25,7.25,1.56$, and 0.39 $\mu \mathrm{M})$ and the Y-axis constituted "the response," in the form of the corresponding values of viability $\%$. The slope (a) and the intercept on Y-axis (b) were extracted from the plotted graph. The next step is substitution of $(y)$ in the equation with the viability $\%$ $(50 \%)$, to get the value of $(x)$, which represents log of $\mathrm{IC}_{50}$ of cisplatin, from which $\mathrm{IC}_{50}$ is deduced. Another linear graph was plotted using values of viability \% recorded after laser irradiation of cisplatin-treated cells (Cis+PBM), from which another $\mathrm{IC}_{50}$ should be obtained, to be compared with that obtained without PBM. The importance of plotting this second graph is that yielding a lower $I_{50}$ means a potentiating effect of PBM to cisplatin that caused it to inhibit growth of cancer cells at a lower dose. Nevertheless, the $\mathrm{IC}_{50}$ calculated from the cisplatin-only treatment was only prepared to be further used throughout the experiment.

Table 1: Values of viability \% of MTT assay for cisplatin-alone (Cis) and combination - (Cis+PBM) treated HEp-2 cells at the serial concentrations $100-0.39 \mu \mathrm{M}$

\begin{tabular}{llllll}
\hline \multicolumn{2}{l}{ Cisplatin concentration $(\mu \mathrm{M})$} & & & & \\
\hline & 100 & 25 & 7.25 & 1.56 & 0.39 \\
Cis & 32.22 & 38.84 & 49.05 & 60.93 & 73.72 \\
Cis+PBM & 19.57 & 32.14 & 43.56 & 54.07 & 63.44 \\
\hline
\end{tabular}

Plotted dose-response linear graphs (Figure 1) revealed that $\mathrm{IC}_{50}$ of cisplatin, with no subsequent LLLI was $7.08 \mu \mathrm{M}$, while $\mathrm{IC}_{50}$ calculated for combined cisplatin treatment and PBM was $2.437 \mu \mathrm{M}$.

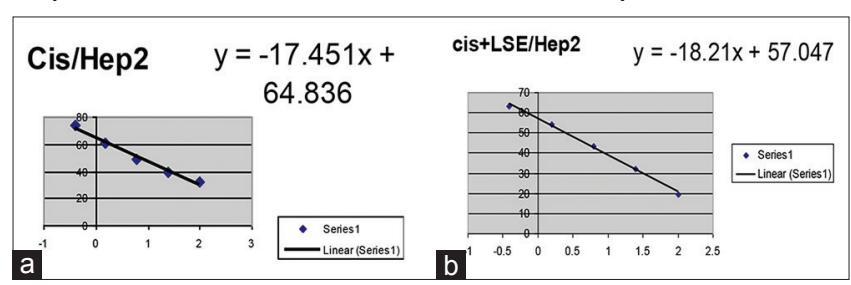

Figure 1: Dose-response linear graphs for calculation of half maximal inhibitory concentration of cisplatin in: cisplatin-only treated HEp-2 cells (a) and in combination cisplatin+PBM treated HEp-2 cells (b)

MTT assay was performed again (in triplicates), on two groups of cells; the first one was $\mathrm{HEp}-2$ cells treated only with cisplatin at $\mathrm{IC}_{50}=7.08$ $\mu \mathrm{M}$ (Cis group) and the second one was HEp-2 cells priorly incubated with cisplatin at $\mathrm{IC}_{50}=7.08 \mu \mathrm{M}$, followed by PBM (Cis+PBM group). The recorded viability $\%$ data were compared to those of control and PBM groups.

\section{ELISA}

The levels of CYC released in cell culture fluid was assessed by the quantitative sandwich ELISA, using CYC human in vitro ELISA kit (\#ab119521) (Abcam, UK). Briefly, CYC present in the sample or standard bound to the monoclonal (capture) antibody coating the wells. Then, the biotin-conjugated anti-CYC monoclonal (detection) antibody was added to bind CYC, which was at this moment sandwiched between the two antibodies. After incubation at room temperature for $2 \mathrm{~h}$, rinsing with the washing buffer was carried out to wash away any unbound antibodies. After that, streptavidinhorseradish peroxidase (HRP) conjugate solution was pipetted into the wells, with subsequent incubation for $1 \mathrm{~h}$ at room temperature. Streptavidin engaged biotin of the detection antibody, which was bound to CYC in the sample or standard. Washing was then implemented to remove any unbound streptavidin-HRP. A chromogenic substrate, 3,3',5,5'-tetramethyl benzidine (TMB), was added to the wells and left to react for $15 \mathrm{~min}$ at $37^{\circ} \mathrm{C}$. A dark blue color developed, as HRP enzyme acted on the TMB substrate and the enzymatic reaction was terminated by adding the stop solution. The absorbance of both the samples and standards was measured by a microplate reader at $450 \mathrm{~nm}$. All measurements were executed in triplicates.

The standard curve (Figure 2) was generated using the known CYC concentrations of the standards (on X-axis) and their measured OD on Y-axis. Hence, unknown CYC concentrations of the samples on $X$-axis were extrapolated through tracing their corresponding recorded $O D$ values on Y-axis.

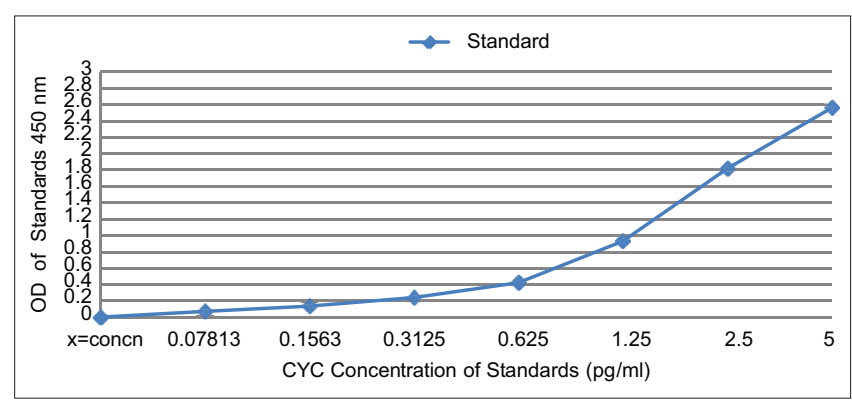

Figure 2: Enzyme-linked immunosorbent assay standard curve for the estimation of cytochrome $c$ concentration $(\mathrm{pg} / \mathrm{ml})$

\section{Microscopic examination}

After slide preparation, hematoxylin and eosin (H\&E) staining of the fixed cells was conducted as the slides were rehydrated by dipping them in descending concentrations of alcohol $(100 \%, 90 \%$, and $75 \%$ then $50 \%$ ethanol), then were rinsed in distilled water for $5 \mathrm{~min}$. This was followed by immersing the slides in filtered Mayer's hematoxylin solution for $3 \mathrm{~min}$, succeeded by washing with distilled water twice. Afterward, the slides were immersed in eosin stain for $5 \mathrm{~s}$, followed by rinsing with distilled water. The stained slides were dehydrated by putting them in ascending concentrations of ethanol, and then were soaked in xylene for $10 \mathrm{~min}$. The final step was adding one small drop of the mounting medium to the slide, and then placing a clean coverslip onto it. The slides were left to dry to get ready for examination. 


\section{Assessment of H\&E-stained HEp-2 cells}

Cytological exploration and photomicrography

H\&E-stained slides were photomicrographed at an original magnification power of $\times 100$ (oil immersion) using a digital camera (EOS 650D, Canon, Japan) which was mounted on a light microscope (BX60, Olympus, Japan), in the Precision Measurement Unit, Oral Pathology Department, Faculty of Dentistry, Ain Shams University. The captured images were instantly stored on the computer system for further analysis. Microscopic fields showing the presence of the highest number of apoptotic cells were selected. The photomicrographs were carefully inspected for the morphological signs of cell death.

\section{Nuclear morphometric analysis}

The digital photomicrographs were analyzed using image analysis software (Image J, 1.41a, NIH, USA). Images were first corrected for brightness and contrast. Corrected images were then converted into 8-bit grey scale type. Phase coloration of the darkest areas was automatically done. Thresholding was finely adjusted to mark the nuclei of HEp-2 cells. Finally, the nuclear circularity (Circ) and surface area (SA) were automatically measured. NAF was calculated according to the following formula [15].

Nuclear area factor $=$ Circularity $\times$ Object area

\section{Statistical analysis}

Numerical data pooled from cytotoxicity assay in (the form of viability \%), ELISA (in the form of CYC concentration in $\mathrm{pg} / \mathrm{ml}$ ), and nuclear morphometric analysis (in the form of NAF values) were tabulated in Microsoft Excel sheet, then inserted using the Statistical Package for the Social Sciences software, version 25.0 (IBM Corporation, Armonk, NY, USA). Data were presented as mean \pm standard deviation. Comparisons between groups were achieved using analysis of variance (ANOVA) with multiple comparisons post hoc test. $p<0.05$ was considered statistically significant.

\section{Results}

\section{MTT assay results}

The recorded viability \% data of all treatment groups are shown in Table 2 and illustrated in Figure 3.

ANOVA test showed a highly statistically significant difference in the mean viability \% among all groups ( $p$ $=0.000$ ). Post hoc multiple-comparison test revealed that the decrease in viability \% after LLLI only in PBM group, compared to control group, was negligible
Table 2: Mean \pm SD of viability $\%$ of all experimental groups; control, PBM-only treated (PBM), cisplatin-only treated (Cis) and combination cisplatin+PBM (Cis+PBM)

\begin{tabular}{|c|c|c|c|c|c|}
\hline Viability \% & Control & PBM & Cis & Cis+PBM & $p$-value \\
\hline & $100^{\mathrm{a}} \pm 0.0$ & $93^{\mathrm{a}} \pm 1.79$ & $49.9^{b} \pm 3.56$ & $41.3^{c} \pm 2.7$ & $0.000^{*}$ \\
\hline
\end{tabular}

and insignificant $(p=0.062)$. As regard the treatment groups $\mathrm{Cis}$ and $\mathrm{Cis}+\mathrm{PBM}$, there was a statistically high significant drop in mean viability $\%$, in contrast to either control group or PBM group $(p=0.000)$. Interestingly, the decrease in mean viability $\%$ from $\mathrm{Cis}$ to $\mathrm{Cis}+\mathrm{PBM}$ was statistically significant $(p=0.018)$.

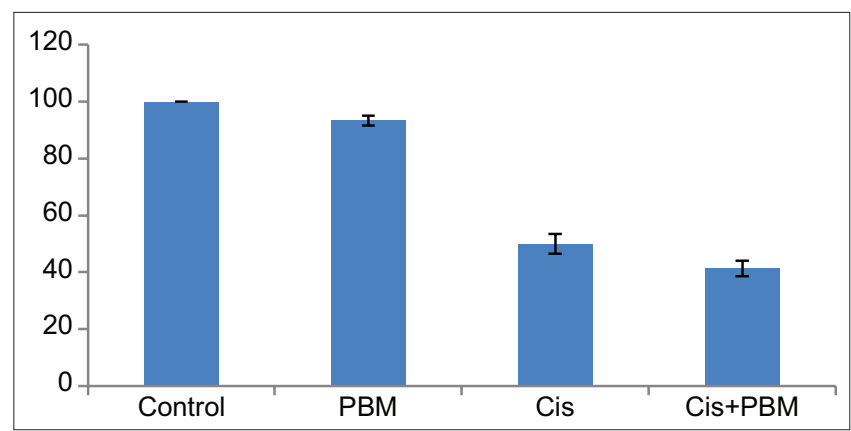

Figure 3: A bar chart showing the mean values of viability \% of all study groups; control, PBM-only treated (PBM), cisplatin-only treated (Cis), and combination cisplatin+PBM (Cis+PBM)

\section{ELISA results}

The mean values of CYC concentration in all groups are demonstrated in Table 3 and Figure 4.

Table 3: Mean \pm SD of CYC concentration $(\mathrm{pg} / \mathrm{ml})$ in all experimental groups; Control, PBM-only treated (PBM), cisplatin-only treated (Cis), and combination cisplatin+PBM (Cis+PBM)

\begin{tabular}{llllll}
\hline CYC concentration & Control & PBM & Cis & Cis+PBM & $p$-value \\
\hline & $0.08^{\mathrm{a}} \pm 0.01$ & $0.19^{\mathrm{b}} \pm 0.00$ & $0.56^{\mathrm{c}} \pm 0.01$ & $0.63^{\mathrm{d}} \pm 0.01$ & $0.000^{*}$ \\
\hline${ }^{*}$ Significance is at $p<0.05$. Different superscripts mean that the statistical difference between groups is
\end{tabular}
significant.

ANOVA test showed a highly statistically significant difference in the mean viability $\%$ among all groups $(p=0.000)$. Post hoc multiple-comparison test

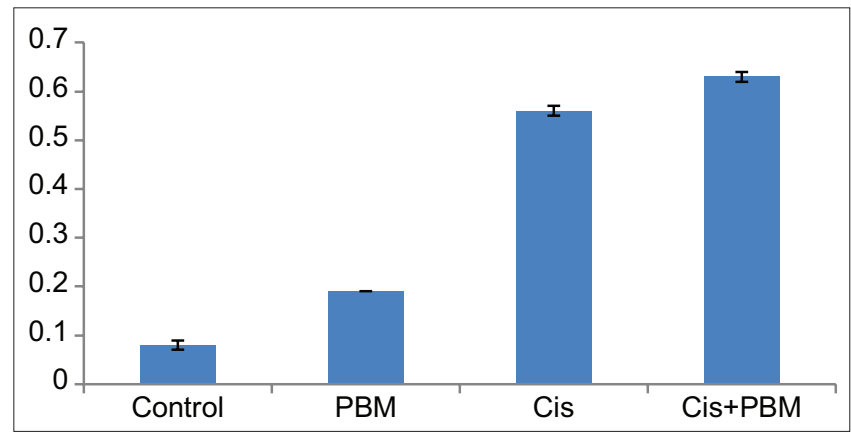

Figure 4: A bar chart demonstrating the mean values of $C Y C$ concentrations $(\mathrm{pg} / \mathrm{ml})$ in all study groups; control, PBM-only treated $(P B M)$, cisplatin-only treated (Cis), and combination cisplatin+PBM (Cis+PBM)

demonstrated a high statistically significant increase in mean CYC concentration from control to PBM to Cis and finally to Cis+PBM ( $p=0.000$, between all). In other words, all modes of treatments in this work significantly 
boosted CYC release, in comparison toCYC basal level in control untreated HEp-2 cells.

\section{Microscopic examination results}

The microscopic findings obtained after close examination of digital photomicrographs of H\&Estained HEp-2 cells in all groups are summarized in Figure 5.

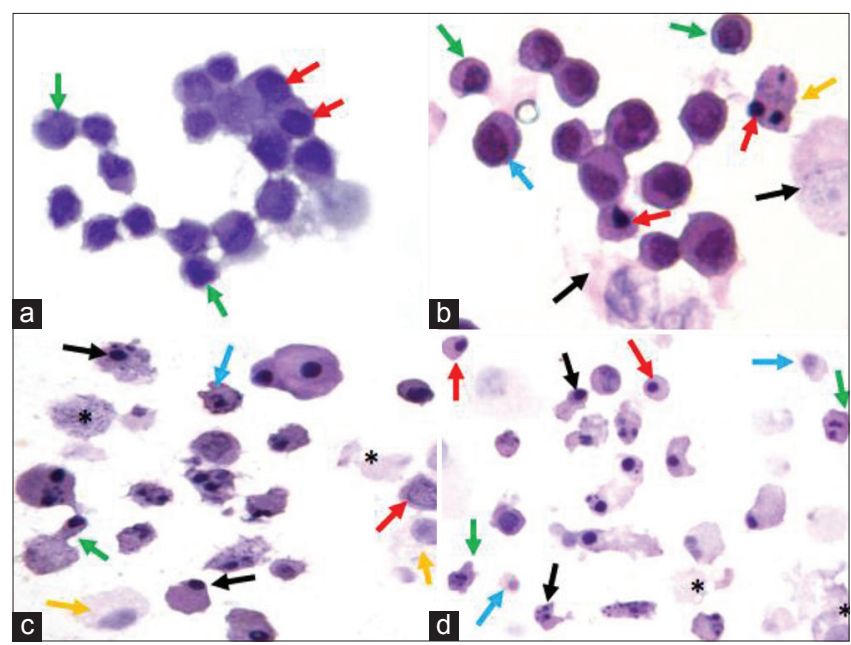

Figure 5: A photomicrograph of (a)control group exhibiting fairly cohesive HEp-2 cells with cellular and nuclear variations in size/ shape (pleomorphism), along with hyperchromatism (red arrows); (b) PBM group showing apoptotic HEp-2 cells with a rounded up outline (green arrows), demonstrating peripheral chromatin condensation along with irregular nuclear outline (blue arrow), pyknotic nuclei undergoing nuclear fragmentation (red arrows), plasma membrane blebbing (orange arrow), and some intervening necrotic cells characterized by swollen cell bodies and oncotic lightly basophilic nuclei (black arrows); (c) Cis group displaying HEp-2 cells with chromatin margination (red arrow), generalized shrinkage in cell bodies with extensive membrane blebbing (blue arrow), budding of apoptotic body (green arrow), nuclear pyknosis with multifragmentation (black arrows), in addition to the presence of necrotic cells (yellow arrows) and cellular debris (asterisks); (d) Cis+PBM group displaying HEp-2 cells with a remarkable reduction in cellular size (red arrows), an extremely irregular outline due to brisk membrane blebbing (green arrows), apoptotic bodies formation (blue arrows), pyknotic nuclei with evident fragmentation in many of them (black arrows), and the presence of necrotic cells and cellular debris (asterisks) (H\&E, $\times 1000$ oil)

\section{Nuclear morphometric analysis results}

An illustration of NAF estimation by Image $J$ software is shown in Figure 6. The mean values of NAF of HEp-2 cells in all experimental groups are shown in Table 4 and Figure 7.

ANOVA test showed a highly statistically significant difference in the mean viability \% among all groups $(p=0.000)$. Post hoc multiple-comparison test revealed a high statistically significant decrease in mean NAF in all treatment groups (PBM, Cis, and Cis+PBM) in comparison to control $(p=0.000)$. The reduction in mean NAF in both $\mathrm{Cis}$ and Cis+PBM groups was also high statistically significant in relation to PBM $(p=0.000)$. However, the decline in mean value

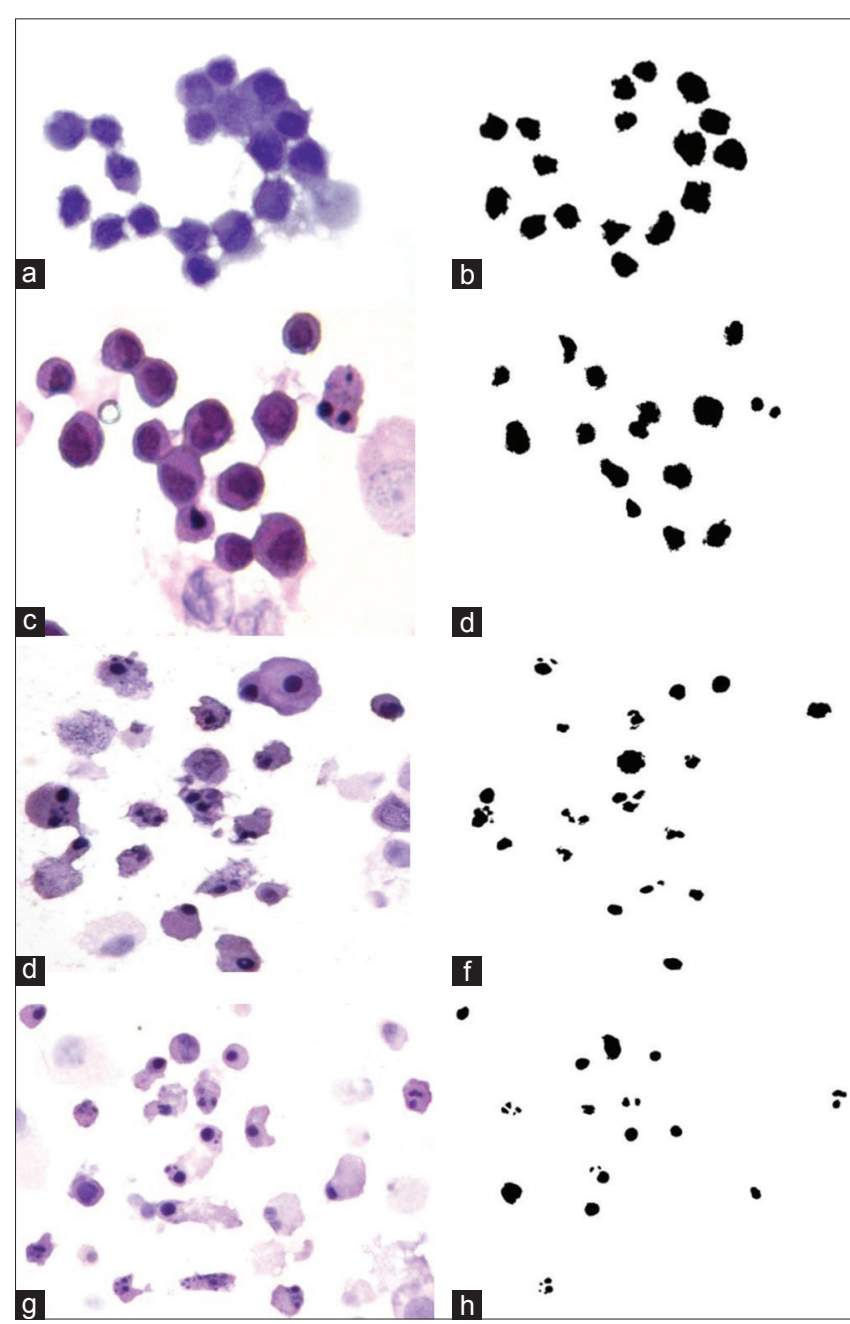

Figure 6: Nuclear morphometric analysis of HEp-2 cells by Image $J$ software showing control cells (a); cells of PBM group (c); Cis group (e); Cis+PBM group (g) and their corresponding estimate of NAF (b), (d), (f) and (h), respectively

of NAF recorded from Cis to Cis+PBMwas statistically nonsignificant $(p=0.252)$.

Table 4: Mean \pm SD of NAF in all experimental groups; Control, PBM-only treated (PBM), cisplatin-only treated (Cis) and combination cisplatin+PBM (Cis+PBM)

\begin{tabular}{|c|c|c|c|c|c|}
\hline NAF & Control & PBM & Cis & Cis+PBM & $\mathrm{p}$-value \\
\hline & $26961.52^{\mathrm{a}} \pm$ & $22284.41^{b} \pm$ & $5153.37^{\circ} \pm$ & $3595.07^{\circ} \pm$ & $0.000^{*}$ \\
\hline & 12277.27 & 10965.43 & 4468.03 & 3480.95 & \\
\hline
\end{tabular}
significant.

\section{Discussion}

The conventional therapeutic approach for HNC entails surgical resection of operable tumors, followed by chemo/radiotherapy [16]. Cisplatin is one of the most potent cytotoxic chemotherapeutic drugs that can be introduced alone or in combination with other chemotherapeutics [17]. Unfortunately, cisplatin has a serious multi-organ toxicity profile that includes nephrotoxicity, ototoxicity, hepatotoxicity, and myelotoxicity [18]. Therefore, the treatment 


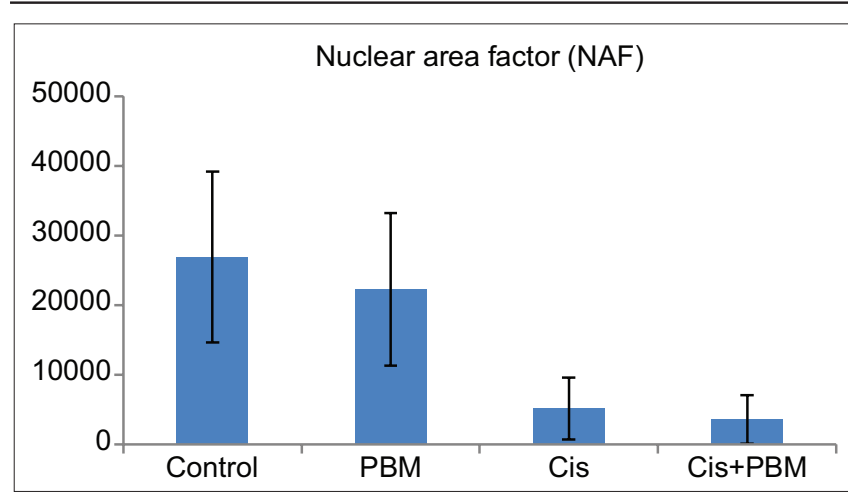

Figure 7: A bar chart showing the mean values of NAF in all study groups; Control, PBM-only treated (PBM), cisplatin-only treated (Cis), and combination cisplatin $+P B M($ Cis $+P B M)$

paradigms of HNC are constantly evolving to improvise novel modalities that can attenuate the toxicities associated with the administration of high doses of chemotherapy. One of these emerging treatment approaches is laser photochemotherapy, which made the possibility of combining PBM (through the application of LLLI) and a potent cytotoxic agent like cisplatin a sought-after approach by investigators over the past decade [19], [20], [21], [22]. The literature, de facto, lacks enough consistency and clarity, regarding the assessment of PBM effect on different cancer cell lines, with many conflicting results due to variable dosimetry [23], [24], [25].

In the present study, PBM at remarkably HF $\left(190.91 \mathrm{~J} / \mathrm{cm}^{2}\right)$ was combined with cisplatin treatment for the first time in literature and this was considered a safe approach that guaranteed that we have already bypassed the window of photobiostimulation, reported in the previous studies [23], [24].

Mitochondria are a common signaling hub for both cisplatin and PBM. The antitumor effect of cisplatin is fundamentally exerted through cross-linking mitochondrial DNA, to form non-functional adducts, causing transcription blockage and impaired synthesis of many electron transport chain (ETC) components. Subsequently, reactive oxygen species (ROS) build up to provoke a state of mitochondrial oxidative stress, leading to the release of CYC to the cytosol to activate the caspases accomplishing apoptotic death [4], [26]. The phototoxic effect of PBM was explained by Karu [27], who reported that LLLI brings about an overall shift in the intracellular redox status and tilts the balance toward greater oxidation. Likewise, when LLLI is operated at a high dose (fluence), Cox, the primary photoacceptor, will be overexcited and oxidated, to the extent that the enzyme fails to keep normal streaming of electrons. This theory was proved eventually in many studies [10], [11], [12], [13] which showed that HF-LLLI promote molecular rearrangements and conformational changes in Cox structure, rendering it functionless. Consequently, electrons in ETC accumulate, with the subsequent outbreak of ROS, giving rise to lethal oxidative stress that signals for mitochondrial apoptotic demise. Our result regarding significant CYC release in PBM-treated HEp-2 cells is in line with that obtained by $\mathrm{Wu}$ et al. [11] who irradiated lung adenocarcinoma ASTC-a-1 cells, at a fluence of $120 \mathrm{~J} / \mathrm{cm}^{2}$.

In the current study, the synergistic effect of PBM to cisplatin was depicted during $\mathrm{IC}_{50}$ calculation, when the theoretically calculated value for cisplatin (with the use of graded concentrations) followed by PBM dropped to $2.4377 \mu \mathrm{M}$ instead of $7.08 \mu \mathrm{M}$, which was deduced on individual cisplatin treatment. This provided early insight into the possible synergistic effect of PBM addition to cisplatin on HEp-2 cells. Moreover, MTT assay results confirmed this idea, as the combined cytotoxic effect of cisplatin and PBM was more significant than that achieved by cisplatin and PBM, when applied separately.

It is noteworthy to mention that it might seem like there was a discrepancy between the insignificant effect of PBM alone on viability of HEp-2 cancer cells and the significant influence of it on potentiating CYC levels in irradiated cancer cells. Nevertheless, Schalch et al. [28] explained this finding by the fact that the laser photons are capable of boosting the activity of some NADHassociated mitochondrial dehydrogenases such as succinate dehydrogenase, affecting the oxidoreduction reaction of MTT assay. Besides, superoxide anions produced on PBM can directly reduce the tetrazolium salt into formazan, producing an overrated estimation of the viability fraction [29]. Therefore, it is highly recommended to use more than one method to assess viability in PBM-treated cells, like the neutral red test, which depends on the status of lysosomal activity [30].

Confirmation of the apoptotic effect of PBM in our study was done, first, through direct visualization of the apoptotic cytomorphologic changes, which predominated the scene and, second, through digital quantitative estimation of NAF, which is a direct function of nuclear circularity and nuclear SA [15]. PBM alone, compared to control, induced a significant decrease in NAF. This decrease was, at the same time, significantly less than that achieved by either cisplatin-only treatment or combination treatment. The photomicrographs reflected these findings, as there were mainly early apoptotic signs [31] in PBM group, in the form of rounding up of cells, nuclear shrinkage with irregular silhouette, chromatin margination, in addition to inconspicuous plasma membrane blebbing and nuclear fragmentation. On the other hand, Cis and Cis+PBM groups exhibited the full-blown morphology of apoptosis [31], with accentuated cellular/nuclear reduction in size and irregular outline, prominent membrane blebbing with active formation of apoptotic bodies and obvious nuclear pyknosis and fragmentation. However, comparing Cis to Cis+PBM, it was found that PBM did not add any significant cytomorphologic changes to those produced by cisplatin alone. This can be explained that PBM acts basically on the molecular level, as proved by significant stimulation of CYC 
release, but it might need more frequent application to allow such molecular alterations to be mirrored on the cytomorphological level.

All in all, cisplatin pre-treatment of HEp-2 cells is thought to represent the primary signal to apoptosis, and then subsequent PBM additionally floods the cell with ROS that further sensitize the cell to respond to cisplatin apoptotic stimuli. Moreover, given the fact that apoptosis is an energy-dependent process [32], so energy derived from PBM can be consumed up by the cellular death arsenal to execute the apoptosis program, as proposed by Diniz et al. [22]. One more mechanism postulated in a previous research stated that cisplatin is a heat- and light-activated chemical agent, so it may be activated by laser light [33].

\section{Conclusion}

Based on the current findings, low-level laser photochemotherapy might be a promising adjunctive anticancer treatment for laryngeal cancer, as PBM, performed through HF-LLLI, enhances the apoptotic effect of cisplatin on HEp-2 cells, as proved by augmentation of CYC release and induction of cytomorphological alterations, compatible with the apoptotic stigmata. PBM alone has also an apoptotic effect on HEp-2 cells. Hence, laser photochemotherapy may introduce a novel treatment modality for HNC, making the possibility of lowering cisplatin dosage plausible, through local control of the neoplasm by PBM, with consequent alleviation of the grave concomitant side effects. In this way, cisplatin-associated morbidity and mortality will be reduced, bringing hope to cancer patients for experiencing a better quality of life.

\section{Recommendations}

Despite the obvious apoptotic effect of PBM at $\mathrm{HF}$, in addition to its anticancer enhancing effect on cisplatin treatment in HEp-2 cells, our results need to be further solidified and validated by intense future research in the area of photochemotherapy, using different dosimetry parameters and different HNC cell lines.

\section{References}

1. Siegel RL, Miller KD, Jemal A. Cancer statistics, 2019. CACancer J Clin. 2019;69:7-34. https://doi.org/10.3322/caac.21551 PMid:30620402

2. Peddi P, Shi R, Nair B, Ampil F, Mills GM, Jafri SH.Cisplatin, cetuximab, and radiation in locally advanced head and neck squamous cell cancer: A retrospective review. Clin Med Insights
Oncol. 2015;9:1-7. https://doi.org/10.4137/CMO.S18682

PMid:25628515

3. Yang Z, Schumaker LM, Egorin MJ, Zuhowski EG, Guo Z, Cullen KJ. Cisplatin preferentially binds mitochondrial DNA and voltage-dependent anion channel protein in the mitochondrial membrane of head and neck squamous cell carcinoma: Possible role in apoptosis. Clin Cancer Res. 2006;12:5817-25. https://doi.org/10.1158/1078-0432.CCR-06-1037 PMid:17020989

4. Hong JY, Hara K, Kim JW, Sato EF, Shim EB, Cho KH. Minimal systems analysis of mitochondria dependent apoptosis induced by cisplatin. Korean J Physiol Pharmacol. 2016;20:367-78. https://doi.org/10.4196/kjpp.2016.20.4.367 PMid:27382353

5. Mester E, Korényi-Both A, Spiry T, Scher A, Tisza S. Stimulation of wound healing by means of laser rays (clinical and electron microscopical study). Acta Chir Acad Sci Hung. 1973;14(4):347-56.

PMid:4787498

6. Elshenawy HM, Eldin AM, Abdelmonem MA. Clinical assessment of the efficiency of low level laser therapy in the treatment of oral lichen planus. Open Access Maced J Med Sci. 2015;3:717-21. https://doi.org/10.3889/oamjms.2015.112 PMid:27275315

7. Stebbing AR. Hormesis--the stimulation of growth by low levels of inhibitors. Sci Total Environ. 1982;22:213-34. https://doi. org/10.1016/0048-9697(82)90066-3 PMid:7043732

8. Huang YY, Sharma SK, Carroll J, Hamblin MR. Biphasic dose response in lowlevel light therapy an update. Dose Response. 2011;9:602-18. https://doi.org/10.2203/dose-response.11-009. Hamblin

PMid:22461763

9. Wang F, Chen TS, Xing D, Wang JJ, Wu YX. Measuring dynamics of caspase-3 activity in living cells using FRET technique during apoptosis induced by high fluence low-power laser irradiation. Lasers Surg Med. 2005;36:2-7. https://doi. org/10.1002/lsm.20130

PMid: 15662635

10. Wu S, Xing D, Wang F, Chen T, Chen WR. Mechanistic study of apoptosis induced by high-fluence low-power laser irradiation using fluorescence imaging techniques. J Biomed Opt. 2007;12(2):064015. https://doi.org/10.1117/1.2804923 PMid:18163831

11. Wu S, Xing D, Gao X, Chen WR. Highfluence low-power laser irradiation induces mitochondrial permeability transition mediated by reactive oxygen species. J Cell Physiol. 2009;218(3):603-11. https://doi.org/10.1002/jcp.21636 PMid:19006121

12. WuS, Zhou F, Wei $Y$, Chen WR, Chen Q, Xing D. Cancer phototherapy via selective photoinactivation of respiratory chain oxidase to trigger a fatal superoxide anion burst. Antioxid Redox Signal. 2014;20:733-46. https://doi.org/10.1089/ars.2013.5229 PMid:23992126

13. Lu C, Zhou F, Wu S, Liu L, Xing D. Phototherapy-induced antitumor immunity: Long-term tumor suppression effects via photoinactivation of respiratory chain oxidase-triggered superoxide anion burst. Antioxid Redox Signal. 2016;24:249-62. https://doi.org/10.1089/ars.2015.6334 PMid:26413929

14. Terpiłowska S, Siwicka-Gieroba D, Siwicki AK. Cell viability in normal fibroblasts and liver cancer cells after treatment with iron (III), nickel (II), and their mixture. J Vet Res. 2018;62:535-42. https://doi.org/10.2478/jvetres-2018-0067

PMid:30729213 
15. Daniel B, DeCoster MA. Quantification of sPLA2-induced early and late apoptosis changes in neuronal cell cultures using combined TUNEL and DAPI staining. Brain Res Brain Res Protoc. 2004;13:144-50. https://doi.org/10.1016/j. brainresprot.2004.04.001 PMid:15296851

16. Cognetti DM, Weber RS, Lai SY. Head and neck cancer: An evolving treatment paradigm. Cancer. 2008;113(7 Suppl):191132. https://doi.org/10.1002/cncr.23654 PMid:18798532

17. Karabajakian A, Gau M, Reverdy T, Neidhardt EM, Fayette J. Induction chemotherapy in head and neck squamous cell carcinoma: A question of belief. Cancers (Basel). 2018;11(1):15. https://doi.org/10.3390/cancers11010015 PMid:30583519

18. Astolfi L, Ghiselli S, Guaran V, Chicca M, Simoni E, Olivetto E, et al. Correlation of adverse effects of cisplatin administration in patients affected by solid tumours: A retrospective evaluation. Oncol Rep. 2013;29(4):1285-92. https://doi.org/10.3892/ or.2013.2279

PMid:23404427

19. Heymann PG, Mandic R, Kämmerer PW, Kretschmer F, Saydali A, Neff A, et al. Laser-enhanced cytotoxicity of zoledronic acid and cisplatin on primary human fibroblasts and head and neck squamous cell carcinoma cell line UM-SCC-3. J Craniomaxillofac Surg. 2014;42(7):1469-74. https://doi. org/10.1016/j.jcms.2014.04.014

PMid:24947610

20. Heymann PG, Ziebart $T$, Kämmerer PW, Mandic $R$, Saydali A, Braun A, et al. The enhancing effect of a laser photochemotherapy with cisplatin or zolendronic acid in primary human osteoblasts and osteosarcoma cells in vitro. J Oral Pathol Med. 2016;45(10):803-9. https://doi.org/10.1111/jop.12442 PMid:27122094

21. Heymann PG, Henkenius KS, Ziebart T, Braun A, Hirthammer K, Halling $\mathrm{F}$, et al. Modulation of tumor cell metabolism by laser photochemotherapy with cisplatin or zoledronic acid in vitro. Anticancer Res. 2018;38(3):1291-301. https://doi.org/10.21873/ anticanres.12351

PMid:29491052

22. Diniz IM, Souto GR, Freitas ID, de Arruda JA, da Silva JM, Silva TA, et al. Photobiomodulation enhances cisplatin cytotoxicity in a culture modelwith oral cell lineages. Photochem Photobiol. 2020;96(1):182-90. https://doi.org/10.1111/ php.13152

\section{PMid:31424557}

23. Pinheiro $A L$, Do Nascliento $S C$, de Vieira $A L$, Rolim $A B$, da Silva PS, Brugnera A Jr. Does LLLT stimulate laryngeal carcinoma cells? An in vitro study. Braz Dent J. 2002;13(2):10912. https://doi.org/10.1590/S0103-64402002000200006 PMid:12238800.

24. Henriques ÁC, Ginani F, Oliveira RM, Keesen TS, Barboza CA, Rosha HA, et al. Low-level laser therapy promotes proliferation and invasion of oral squamous cell carcinoma cells. Lasers Med Sci. 2014;29(4):1385-95. https://doi.org/10.1007/ s10103-014-1535-2

PMid:24526326

25. Liang WZ, Liu PF, Fu E, Chung HS, Jan $\mathrm{CR}$, Wu CH, et al. Selective cytotoxic effects of low power laser irradiation on human oral cancer cells. Lasers Surg Med. 2015;47(9):756-64. https://doi.org/10.1002/lsm.22419 PMid:26395333

26. Yang Z, Schumaker LM, Egorin MJ, Zuhowski EG, Guo Z, Cullen KJ. Cisplatin preferentially binds mitochondrial DNA and voltage-dependent anion channel protein in the mitochondrial membrane of head and neck squamous cell carcinoma: Possible role in apoptosis. Clin Cancer Res. 2006;12(19):581725. https://doi.org/10.1158/1078-0432.CCR-06-1037 PMID: 17020989

27. Karu T. Primary and secondary mechanisms of action of visible to near-IR radiation on cells. J Photochem Photobiol B. 1999;49:1-17. https://doi.org/10.1016/S1011-1344(98)00219-X PMid: 10365442

28. Schalch TD, Fernandes MH, Rodrigues MF, Guimarães DM, Nunes FD, Rodrigues JC, et al. Photobiomodulation is associated with a decrease in cell viability and migration in oral squamous cell carcinoma. Lasers Med Sci. 2019;34(3):629-36. https://doi.org/10.1007/s10103-018-2640-4 PMid:30232646

29. Wang S, Yu H, Wickliffe JK. Limitation of the MTT andXTT assays for measuring cell viability due to superoxide formationinduced by nano-scale TiO2. Toxicol In Vitro. 2011;25:2147-51. https:// doi.org/10.1016/j.tiv.2011.07.007

PMid:21798338

30. Van Tonder A, Joubert AM, Cromarty AD. Limitations of the 3-(4,5-dimethylthiazol-2-yl)-2,5-diphenyl-2H-tetrazolium bromide (MTT) assay when compared to three commonly usedcell enumeration assays. BMC Res Notes. 2015;8:47. https://doi.org/10.1186/s13104-015-1000-8 PMid:25884200

31. Elmore SA, Dixon D, Hailey JR, Harada T, Herbert RA, Maronpot RR, et al. Recommendations from the INHAND apoptosis/necrosis working group. Toxicol Pathol. 2016;44(2):173-88. https://doi.org/10.1177/0192623315625859 PMid:26879688

32. Zamaraeva MV, Sabirov RZ, Maeno E, Ando-Akatsuka $Y$ Bessonova SV, Okada Y. Cells die with increased cytosolic ATP during apoptosis: A bioluminescence study with intracellularluciferase. Cell Death Differ. 2005;12(11):1390-7. https://doi.org/10.1038/sj.cdd.4401661

PMid: 15905877

33. Paiva MB, Joo J, Abrahão M, Ribeiro JC, Cervantes O, SercarzJA Update on laser photochemotherapy: An alternative for cancer treatment. Anticancer Agents Med Chem. 2011;11(8):772-9. https://doi.org/10.2174/187152011797378742 PMid:21906013 